\title{
Occurrences of vegetation fires in Curitiba-PR wildland-urban interface, from 2011 to 2015
}

\author{
Heitor Renan Ferreira ${ }^{1}$, Antonio Carlos Batista ${ }^{1}$, Alexandre França Tetto ${ }^{1}$, Bruna Kovalsyki ${ }^{1}$, João \\ Francisco Labres dos Santos ${ }^{l}$
}

\author{
${ }^{1}$ Universidade Federal do Paraná, Curitiba, Paraná, Brasil. \\ Contact e-mail: *bmheitorf@gmail.com
}

\begin{abstract}
Vegetation fires cause direct and indirect damage to flora, fauna, soil and humans. With the increasing urbanization of the earth's surface, vegetation is increasingly dividing its space with anthropic occupations, thus increasing the wildland-urban interface. The knowledge of the spatial distribution of occurrences of vegetation fires in a locality enables managers to develop and implement a policy to prevent and combat fires. The objective of this study was to spatialize the occurrences of vegetation fires in the city of Curitiba, Paraná, from 2011 to 2015, relating with the monitoring map for the coverage and land use in Brazil in 2016. Data regarding the fires were obtained of the Occurrence Registration and Statistics System SysBM-CCB, version 3.31 of the Paraná State Military Fire Department. The monitoring map for the coverage and land use was obtained from the Brazilian Institute of Geography and Statistics (IBGE). After consistency of the data, the validity of 1,255 occurrences was verified, and from this total it was observed that 208 fires (16.6\%) occurred on the highways, offering a danger to the visibility of vehicle traffic. For the mapping of occurrences in the map provided by IBGE, 997 occurrences of the total obtained $(79.4 \%)$ were considered because they presented specific information for their location. Of this total, 905 occurrences $(90.8 \%)$ were observed in areas of the municipality classified by the IBGE as "artificial areas", characterized as areas with predominance of non-agricultural anthropic surfaces. The other occurrences were distributed in the classifications "mosaic of occupations in forest area", "forest vegetation", "country vegetation" and "mosaic of occupations in country area", occupying respectively $76(7.6 \%)$, nine $(0.9 \%)$, five $(0.5 \%)$ and two occurrences $(0.2 \%)$. From the results obtained, it can be concluded that in Curitiba the predominance of fires occurs in anthropic areas, being necessary to direct public policies of fire prevention to the public of these areas.
\end{abstract}

Keywords: fire statistic, fire distribution, fire 